Www.jmscr.igmpublication.org

Impact Factor (SJIF): 6.379

Index Copernicus Value: 79.54

ISSN (e)-2347-176x ISSN (p) 2455-0450

crossrefDOI: https://dx.doi.org/10.18535/jmscr/v6i10.212

Journal Of Medical Science And Clinical Research

IGM Publication

An official Publication of IGM Publication

\title{
Comparative study of Closed Reduction and Cast, versus Percutaneous K Wire Fixation of Extra Articular Distal End Radius Fracture in a Tertiary Care Centre
}

Authors

\section{Dr Sanjay Rajkamal Bharti, Dr Sagar Zopate}

SVNGMC Yavatmal

Corresponding Author

Dr Sanjay Rajkamal Bharti

Shri Vasantrao Naik Government Medical College [SVNGMC] Yavatmal, Maharashtra, India

Email: drkiranbharti@gmail.com, Phone: 9850198606

\begin{abstract}
Distal end radius fractures represent one of the commonest fractures treated in emergency department. Though management of distal end radius fractures has changed over the period of time from cast immobilization to operative intervention, there are conflicting data about long term relationship regarding radiographic parameters and patient report outcome. We compared the outcome of fractures of the lower end radius treated with closed reduction and cast immobilization and those treated with percutaneous $K$ wire fixation and immobilization in cast in neutral position.

Aims and Objectives: To study postoperative functional outcome and complications in patients treated for extra articular fracture of distal end of radius and to compare the role of closed reduction and cast and percutaneous $K$ wire fixation and cast application in management of fracture distal end of radius.

Materials and Methods: 40 cases of extraarticular lower end of radius fracture were treated. These 40 cases were divided randomly in two equal groups consisting of 20 patients each. One group was treated with closed reduction and below elbow cast and other group by percutaneous $K$ wire fixation and below elbow cast.In both the groups radiological and clinical evaluation was done by taking serial AP and lateral view of wrist joint at 4 weeks, 8weeks and finally at 12 weeks. The assessment of results were made using the demerit score system of Gartland and Werley based on objective and subjective criteria, residual deformity and complications.

Results: Our results showed excellent outcome in 8 patients treated by percutaneous $K$ wire fixation and in 6 patients treated by closed reduction and cast alone. When compared both groups anatomical reduction was maintained better in $K$ wire group. Patients in cast group developed progressive dorsal angulation, loss of radial length and radial inclination. $K$ wire group had statistically significant better radiological outcome except for ulnar variance and bone healing than cast group. However functional outcome was similar in both groups

Keywords: Closed Reduction Cast versus percutaneous $K$ wire fixation, extra articular radial fractures.
\end{abstract}

\section{Introduction}

Colles' fracture is the most common fracture seen in orthopedic practice, but no consensus has been reached on an effective method to maintain the initial reduction achieved. ${ }^{[1]}$ 


\section{Mechanism of injury}

Fall on outstretched hand with wrist in hyperextension is the usual mode of injury either involving vehicular accident (notably motor cycle accident), blow on closed fist or fall from height on level ground. With the wrist in 40 degree to 90 degree dorsiflexion, a fall on outstretched hand produces a distal radius fracture with dorsal displacement. The injury pattern depends on the magnitude and direction of force and physical properties of bone.

The comminuted fracture in the younger patient is generally a high energy injury secondary to either a fall from a height or high speed motor vehicle accident. With dorsiflexion, the radius fracture in tension on its palmar surface followed by compression on the dorsal surface, results in dorsal comminution. The lunate can exert a compression force on distal radius producing a depressed fracture of the lunate fossa the so called die punch fracture, similarly a scaphoid fossa depression fracture can result from compressive forces exerted by the scaphoid. The ulnar styloidfracture so often seen with distal radius fractures probably represents an avulsion fracture from a tensile force transmitted through on intact triangular fibrocartilage complex. Treatment of such injuries is difficult. These fractures often are unstable, are difficult to reduce anatomically, and are associated with a high prevalence of complications of post-traumatic osteoarthritis after intra- articular fracture of the distal aspect of the radius. It is also known that extra-articular misalignment can lead to decreased grip strength and endurance as well as limited motion and carpal instability. Closed reduction and cast immobilization has been the mainstay of treatment of these fractures, but invariably it results in mal-union, poor functional and cosmetic outcome. $^{[2]}$

In many cases there is weakness of handgrip and return to pre-injury activity level becomes impossible. Closed reduction and cast immobilization often leads to collapse of the radius. ${ }^{[3][4]}$ Percutaneous K-wire fixation provides additional stability and is one of the earliest forms of internal fixation. $^{[5]-[7]}$

Most of the work done with percutaneous pinning emphasizes that there is significant residual stiffness of the hand and wrist ${ }^{[8],[9]}$ The acute palmarflexed position of the wrist during the postoperative immobilization period was blamed as the main reason for stiffness. ${ }^{[10]}$

\section{Current trends in treatment}

Various methods of preventing or minimising the loss of reduction of unstable fractures of the distal radius have been described. These include percutaneous pinning of the distal fragment, immobilisation with pins incorporated in the plaster. $^{[11]}$ external skeletal fixation,limited open reduction with or without bone grafting or bone substitutes and extensive open reduction and internal fixation. ${ }^{[11],[12]}$. Percutaneous pinning has been recommended as a simple way of providing additional stability to immobilisation in a cast in unstable, extra-articular fractures of the distal radius in which anatomical reduction is obtainable.

The results relate more to the quality of and the maintenance of the reduction than to the method of immobilization or fixation used to achieve this end result. If closed means can achieve and maintain an adequate reduction, then these are satisfactory. Function becomes impaired when the deformity exceeds $20^{\circ}$ of dorsal angulation, less than $10^{\circ}$ of radial inclination, or a radial shift of over $2 \mathrm{~mm}$. Shortening is a major problem. Although the exact distances are difficult to quantify, it appears that radial shortening of $6 \mathrm{~mm}$ or more results in an ulnar deformity sufficient to cause significant ulnarsided wrist pain secondary to ulnocarpal impingement. ${ }^{[11]}$

In elderly, osteoporotic patients and in severely comminuted fractures the technique has less favourable results and is therefore considered to be inappropriate however, it is still recommended by some authors because it is simple to use and much less intrusive than other methods such as external fixation. ${ }^{[11],[12]}$ 


\section{Complications of Distal Radius Fractures}

- Compressive neuropathy-median nerve involvement associated with reduction of fracture in emergency room. Radial neuropathy can arise as result of improper immobilization and from external pin fixation.

- Arthrosis after fracture- this is associated with painful motion of the wrist of forearm.

- Malunion results when the fracture is unstable and comminuted

- Tendon inury- rupture of extensor pollicislongus and rupture of index flexor digitorum profundus or flexor pollicislongus. The rupture is related to bone fragments from displaced fractures that abraid the tendon during the weeks after healing of the fracture

- Volkman'sischaemic contracture -this can arise as a result of application of constricting cast.

- Shoulder hand syndrome.

- Stiff hands.

- Unrecognized associated injuries.

- Complex regional pain syndrome.

\section{Materials and Methods}

\section{Selection of Cases}

This study was carried out on patients admitted in orthopaedics ward during the period of one year from January 2017 to December 2017. 40 cases of extraarticular fractures of lower end of radius were treated during the period of one year. These 40 cases were divided randomly in two equal groups consisting of 20 patients each. One group was treated with closed reduction and below elbow cast and other group by percutaneous $\mathrm{K}$ wire fixation followed by below elbow cast in neutral position.

\section{Inclusion criteria}

- Closed extra articular fractures of lower end of radius.

- Age $>20$ years.

- Associated with ulnar styloid fracture.

\section{Exclusion criteria}

- Open fracture-segmental fracture.

- Associated with ulnar fracture.

- Paediatric fracture $<20$ years.
- Polytrauma patients, out of the 40 patients enrolled for the study, none of them were lost to follow-up.

Patients medically unfit for surgery.

Compound fractures associated with vascular injuries.

Patients not willing for surgery

Study design: Randomised clinical trial

Methodology: 40 patients of extraarticular lower end of radius fracture were treated and divided randomly in two equal groups consisting of 20 patients each. One group was treated with closed reduction followed by below elbowcast and other group by percutaneous $\mathrm{K}$ wire fixation and below elbow cast application in neutral position.

Acareful history was elicited from the patients to reveal the mechanism of injury and the severity of trauma. All patients were thoroughly examined. Their general condition, associated systemic diseases and associated injuries were noted. Careful inspection of the deformity, swelling and ecchymosis were done. Clinically tenderness, bony irregularity, crepitus and the relative position of radial and ulnar styloid process were elicited. Movements of the wrist and forearm were checked. Distal vascularity was assessed by radial artery pulsations, capillary filling, pallor and paraesthesia over finger tips. The involved forearm was immobilized in a below elbow POP slab and kept elevated.

Closed reduction was done under fluoroscopic guidance and cast was applied undergeneral anaesthesia in one group, position of immobilization was given according to fracture anatomy. Cast was removed after 6 weeks and mobilization started.

While in other group percutaneous $\mathrm{K}$ wire fixation was done under short general anaesthesia. The size of the $\mathrm{K}$ wire was $1.5-2.0 \mathrm{~mm}$. In this group,after $\mathrm{K}$ wire fixation below elbow cast was given in neutral position for 1 month and then mobilization started in the form of active finger, wrist exercises and forearm pronation and supination exercises . K wire was removed after 6 weeks. The number of $\mathrm{K}$ wires used was as per required for fracture stabilization. In both the groups radiological 
evaluation was done by taking serial AP and lateral view of wrist joint at 4 weeks, 8 weeks, and finally at 12 weeks. In both the groups the clinical evaluation was done at 6 weeks and 12 weeks.

Results were evaluated clinically and radiologically by the Sarmiento et al, modification of the demerit point system of Gartland and Werley ${ }^{[13]}$. Average age of the patients in $\mathrm{K}$ wire group was 60 years and that of cast group was 57 years. Mechanism of injury was fall on outstretched hands in $34(85 \%)$ of patients and RTA in $6(15 \%)$. Out of these patients right extremity involved in $24(60 \%)$ and left extremity in $16(40 \%)$ of patients. There were 23 $(57.5 \%)$ female patients and $17(42.5 \%)$ male patients. Ulnar styloid fracture presented in 5 patients and distal radio ulnar joint instability was noted pre operatively in 7 patients as cited in Table no -1. All these patients had closed injury. All the patients had stable wrist joint post operatively.

Results were evaluated clinically and radiologically by the Sarmiento et al, modification of the demerit point system of Gartland and Werley ${ }^{[13]}$. Patients treated by closed reduction and cast application showed excellent outcome in 6 patients $(30 \%)$, good outcome in 9 patients (45\%) and fair outcome in 5 patients $(25 \%)$. Patients treated by percutaneous pinning followed by casts showed excellent outcome in 8 patients (40\%), good outcome 10 $(50 \%)$ and fair outcome in $2(10 \%)$.Total number of 7 patients showed fair outcome which was attributed to severe comminution and swelling at the time of injury as cited in Table no-2

There was no complication in both study groups except for 2 superficial pin tract infections in $\mathrm{K}$ wire group which were controlled by short course of oral antibiotics.

Table no: 1 showing the number and percentage of male, female patients, right or left hand, mechanism of fall and associated injury.

\begin{tabular}{|l|c|c|c|}
\hline Male & 17 & $42.5 \%$ & 40 \\
\cline { 1 - 3 } Female & 23 & $57.5 \%$ & \\
\hline Right & 24 & $60 \%$ & \multirow{2}{*}{$100 \%$} \\
\hline Left & 16 & $40 \%$ & \\
\hline Fall & 34 & $85 \%$ & \multirow{2}{*}{$100 \%$} \\
\cline { 1 - 3 } RTA & 6 & $15 \%$ & \\
\hline Ulnar styloid fracture & 5 & $12.5 \%$ & \\
\cline { 1 - 3 } Radioulnar joint instability & 7 & $17.5 \%$ & \\
\hline
\end{tabular}

Table:2 showing the average age, period of mobilization and Outcome at the end of 12 weeks in both groups.

\begin{tabular}{|l|c|c|c|c|c|c|c|c|c|}
\hline & \multirow{2}{*}{$\begin{array}{c}\text { Nu } \\
\mathrm{mb} \\
\text { er }\end{array}$} & \multirow{2}{*}{$\begin{array}{c}\text { Avera } \\
\text { ge age }\end{array}$} & \multirow{2}{*}{$\begin{array}{c}\text { Mobilizati } \\
\text { on }\end{array}$} & \multicolumn{5}{|c|}{ Outcome } \\
\cline { 5 - 10 } & & & \multicolumn{2}{|c|}{ Good } & \multicolumn{2}{|c|}{ Fair } & \multicolumn{2}{|c|}{ Poor } \\
\hline $\begin{array}{l}\text { Closed } \\
\text { reduction } \\
\text { with Cast }\end{array}$ & 20 & 57 & 6 weeks & 6 & $\begin{array}{c}30 \\
\%\end{array}$ & 9 & $\begin{array}{c}45 \\
\%\end{array}$ & $\begin{array}{c}25 \\
\%\end{array}$ \\
\hline $\begin{array}{l}\text { K wires } \\
\text { with cast }\end{array}$ & 20 & 60 & 4 weeks & 8 & $\begin{array}{c}40 \\
\%\end{array}$ & $\begin{array}{c}1 \\
0\end{array}$ & $\begin{array}{c}50 \\
\%\end{array}$ & 2 & $\begin{array}{c}10 \\
\%\end{array}$ \\
\hline
\end{tabular}

\section{Discussion}

Accurate reduction of the fracture is the first step in the treatment of distal radial fractures. Many options are available to maintain this initial reduction. The most common traditional method is closed reduction and cast immobilization, but this often fails to prevent early radial collapse and is associated with a high risk of malunion, joint stiffness and painful wrist. Hence, this method is recommended for lowdemand elderly patients ${ }^{[14],[15]}$ by some authors because it is simple to use and much less intrusive nature than other methods such as external fixation and plating which can be a choice in younger and more demanding patients. Various techniques of percutaneous pinning are available. Most studies attribute poor results of this technique to radial shortening, wrist stiffness and reflex sympathetic dystrophy. ${ }^{[8],[9]}$

We treated and studied 40 patients ,divided them into two groups .First group was treated with closed reduction and cast alone whereas the in second group $\mathrm{K}$ wire fixation was done followed by cast.

Maximum patients in our study comprised of elderly female patients with a history of fall on outstretched hands. Low intensity trauma leading to fractures very well correlates with the well formulated theory of postmenopausal osteoporotic women with fractures. In older age groups, more women than men have fractures of the distal radius, often resulting from low-energy falls. The relationship between distal radius fracture and osteoporosis has already been postulated. Patients younger than age 65 years had significantly lower bone mineral density (BMD) at the hip compared with age expected values. Currently the World Health Organization advises that fracture of the distal radius in a postmenopausal woman is an indication 
for evaluation of $\mathrm{BMD}^{[16]}$ In our study right side (dominant wrist) was involved in $24(60 \%$ ) patients and the left side was involved in $16(40 \%)$ patients. Results were evaluated clinically and radiologically by the Sarmiento .et .al. modification of the demerit point system of Gartland and Werley ${ }^{[13]}$. Patients treated by closed reduction and cast application showed excellent outcome in 6 patients(30\%),good outcome in 9 patients (45\%) and fair outcome in 5patients $(25 \%)$. Patients treated by percutaneous pinning followed by casts showed excellent outcome in 8 patients (40\%), good outcome $10(50 \%)$ and fair outcome in $2(10 \%)$. Total number of 7 patients showed fair outcome which was attributed to severe comminution and swelling at the time of injury.

When results in both groups were compared, patients in $\mathrm{K}$ wire group showed early improvement in range of motion and grip strength as mobilization was started early in these patients. $\mathrm{K}$ wire group had statistically significant better radiological outcome and the anatomical reduction was maintained better except for ulnar variance. Patients in cast group developed progressive dorsal angulation, loss of radial length and radial inclination. However the final functional outcome was found to be similar in both groups.

Our findings very well correlated with Azzopardi et al. who found that the improvement in functional outcomes for grip strength, range of movement and pain in patients treated by supplementary wires was not statistically significant, except for the range of movement in ulnar deviation. He correlated these with the small differences in radiological parameters which were therefore of no clinical significance. He concluded that supplementary fixation by $\mathrm{K}$-wire was only marginally superior to cast immobilisation alone in reducing displacement of the fracture after closed manipulation. And that supplementary Kwires did not provide better clinical outcomes in unstable, extra-articular, dorsally angulated, fractures of the distal radius. ${ }^{[17]}$

Raghu .B.V..et.al. concluded that closed reduction with percutaneous $\mathrm{K}$ wiring and below elbow cast application is a simple, minimally invasive technique that provides added stability and better radiological outcome with respect to treatment of extra-articular distal radius fracture as compared to closed reduction and below elbow cast application, but the functional outcome between the two treatment modalities is not statistically significant. ${ }^{[18]}$

Our findings were in contrast with Gupta et al. who, in his prospective, randomized study of 50 patients evaluated the efficacy of maintaining reduction and consequent functional end results of two treatment methods, ie, percutaneous crossed-pin fixation followed by plaster of Paris cast immobilization with the wrist in functional position versus conventional plaster of Paris cast immobilization. In his study $40 \%$ patients had good result and $20 \%$ had fair or poor result in cases of plaster cast application, whereas in patients who had K-wire fixation: $18 \%$ had good results and $4 \%$ had fair to poor results. He concluded that the anatomical and functional end results were significantly better with percutaneous crossed-pin fixation at final followup. $^{[1]}$

Rodríguez-Merchán EC et.al found that functional results in the pinning group were better (excellent, 12; good, 6; fair, 2) than in the plaster group (excellent, 3; good, 8; fair, 5; poor, 4). Anatomic results also were better in the pinning group. He concluded that the best anatomic and functional results were obtained by percutaneous pinning. Although the cost of pins and plaster treatment is significantly greater than plaster treatment, the author believed that the positive end result justifies the cost. ${ }^{[19]}$

Abhishek K Das et.al. in his study percutaneous pinning and immobilization of the fracture with wrist immobilized in neutral position found 26 patients $(81.25 \%)$ had excellent hand function ; 4 patients $(12.5 \%)$ had good results; 2 patients $(6.25 \%)$ who had residual displacement and joint stiffness had a fair outcome. Pin loosening was encountered in 13 cases. Pin tract infection $(n=2)$, malunion in $(n=2)$, joint stiffness $(n=2)$, reduced grip strength $(n=2)$ and parasthesia in the distribution of superficial radial nerve $(n=1)$ were the other complications observed. He concluded 
that, percutaneous pinning and immobilization of the fracture with wrist immobilized in neutral position for 3 weeks and early physiotherapy provided anatomic fracture reduction and fixation and allowed earlier rehabilitation without jeopardizing the fracture alignment. ${ }^{[20]}$

The contrasting results in other studies could be possibly due to inclusion of a younger population, male gender and age and gender matched patients with greater bone mineral density, as these factors contribute to healing process of fractures. Though we got a substantial difference in the anatomic and radiological outcome in both the study groups the final functional outcome was similar. The results relate more to the quality of and the maintenance of the reduction than to the method of immobilization or fixation used to achieve this end result. If closed means can achieve and maintain an adequate reduction, then these are satisfactory. ${ }^{[11]}$ Amongst both the groups, the functional outcome of both the groups was found to be same by the scoring system, also the subjective assessment in the scoring system could lead to a difference in functional outcome.

\section{Conclusion}

Distal end of radius fracture is more common in postmenopausal and senile age group having osteoporosis. As being fracture in senile age group low velocity trauma is sufficient to cause distal end radius fracture. Fall on outstretched hand is commonest mode of injury, with the dominant hand i.e right hand being affected more.

Post operative rehabilitation plays important role in functional outcome of distal end radius fracture. Patients in whom early physiotherapy started developed early improvement in range of movements, possible with $\mathrm{K}$ wire fixation. Though radiological and anatomical outcome is better by $\mathrm{K}$ wire fixation than by closed reduction and cast in treatment of extra articular distal end radial fracture , the functional outcome remains the same whether they are treated by $\mathrm{K}$ wire fixation or by closed reduction and cast. However early rehabilitation in $\mathrm{K}$ wire group as compared to the cast alone can be outweighed with the complications associated with percutaneous pinning. As a few researchers got better functional outcome the final choice of treatment could be laid with the patients themselves if they wish for a better, earlier improvement of function and minimal cosmetic disfigurement in long term.

The quality of life has significant difference after treatment by any of above modality.

\section{References}

1. Gupta R, Raheja A, Modi U. Colles' fracture: Management by percutaneous crossed-pin fixation versus plaster of Paris cast immobilization. Orthopedics. 1999 Jul;22(7):680-2.

2. Gofton W, Liew A. Distal radius fractures: Nonoperative and percutaneous pinning treatment options. OrthopClin North Am. 2007;38:175-85. [PubMed]

3. Slagel BE, Luenam S, Pichora DR. Management of post traumatic malunion of fractures of distal radius. OrthopClin North Am. 2007;38:203-16. [PubMed]

4. Arora J, Kapoor H, Malik A, Bansal M. Closed reduction and plaster cast immobilization $\mathrm{Vs}$ external fixation in communited intra-articular fractures of distal radius. Indian J Orthop 2004;38:113-7. Available

from: http://www.ijoonline.com/text.asp?2004/38/ 2/113/40924

5. Castaing J. Recent fractures of the inferior extremity of the radius in the adult. Rev ChirOrthop French. 1964;50:582-696. [PubMed]

6. Mah ET, Atkinson RN. Percutaenous Kirschner wire stabilization following closed reduction of Colles' fractures. J Hand Surg Br. 1992;17(1):55-62. [PubMed]

7. De Palma A. Comminuted fractures of the distal end of the radius treated by ulnar pinning. J Bone Joint Surg Am. 1952;34:651-62. [PubMed]

8. Field J, Atkins RM. Algodystrophy is an early feature after Colles' fracture. What are 
the implications? J Hand Surg Br. 1997;22:178-82. [PubMed]

9. Atkins RM, Duckworth T, Kanis JA. Features of Algodystrophy after Colles' fracture. J Bone Joint Surg Br. 1990;72:10510. [PubMed]

10. Rajan S, Jain S, Ray A, Bhargava $P$. Radiological and functional outcome in extra-articular fractures of lower end radius treated conservatively with respect to its position of immobilization. Indian J Orthop. 2008;42:201-22. [PMC free article] [PubMed]

11. T. S. Axelrod. 10Fractures of the Distal Radius. The Rationale of Operative Fracture Care pp 167-189

12. Simic PM, Weiland AJ. Fractures of the distal aspect of the radius: changes in treatment over the past two decades. Instr Course Lect. 2003;52:185-195. [PubMed]

13. Gartland JJ, Jr, Werley CW. Evaluation of healed Colles' fracture. J Bone Joint Surg Am. 1951;33:895-907. [PubMed]

14. Jupiter JB, Ring D, Weitzel PP. Surgical treatment of redisplaced fracture of the distal radius in patients older than 60 years. J Hand Surg Am. 2002;27:714-23. [PubMed]

15. Ark J, Jupiter JB. The rationale for precise management of distal radius fractures. Orthop Clin N Am. 1993;24:205-10. [PubMed]

16. Douglas P Hanel, Marci D Jones, Thomas E Trumble . Treatment of complex fractures .Wrist Fractures. January 2002Volume 33, Issue 1, Pages 35-57

17. Azzopardi, Ehrendorfer S, Coulton T, Abela M. Unstable extra-articular fractures of the distal radius: A prospective, randomised study of immobilisation in a cast versus supplementary percutaneous pinning.J Bone Joint Surg Br. 2005 Jun;87(6):837-40.
18. Raghu Begur Venkatesh, Gopinath Karpenahalli Maranna, and Roshan Kumar Bangalore Narayanappa. A Comparative Study between Closed Reduction and Cast Application Versus Percutaneous K- Wire Fixation for Extra-Articular Fracture Distal end of Radius.J ClinDiagn Res. 2016 Feb; 10(2): RC05-RC09.Published online 2016 Feb

1. doi: 10.7860/JCDR/2016/18266.7220 PMCID: PMC4800606PMID: 27042540

19. Rodríguez-MerchánEC.Plaster cast versus percutaneous pin fixation for comminuted fractures of the distal radius in patients between 46 and 65 years of age.JOrthop Trauma. 1997 Apr;11(3):212-7.

20. Das AK, Sundaram N, Prasad TG, Thanhavelu SK. Percutaneous pinning for non-comminuted extra-articular fractures of distal radius. Indian J Orthop [serial online] 2011;45:422-

6: http://www.ijoonline.com/text.asp?2011/4 5/5/422/83949 